\title{
Family profiles in eating disorders: family functioning and psychopathology
}

This article was published in the following Dove Press journal:

Psychology Research and Behavior Management

3 October 2017

Number of times this article has been viewed

\author{
Luca Cerniglia' \\ Silvia Cimino \\ Mimma Tafà ${ }^{2}$ \\ Eleonora Marzilli² \\ Giulia Ballarotto ${ }^{2}$ \\ Fabrizia Bracaglia ${ }^{2}$ \\ 'Faculty of Psychology, International \\ Telematic University UNINETTUNO, \\ 2Department of Dynamic and Clinical \\ Psychology, University of Rome "La \\ Sapienza", Rome, Italy
}

\begin{abstract}
Research has studied family functioning in families of patients suffering from eating disorders (EDs), particularly investigating the associations between mothers' and daughters' psychopathological symptoms, but limited studies have examined whether there are specific maladaptive psychological profiles characterizing the family as a whole when it includes adolescents with anorexia nervosa (AN), bulimia nervosa (BN), and binge eating disorder (BED). Through the collaboration of a network of public and private consultants, we recruited $n=181$ adolescents diagnosed for EDs ( $n=61$ with $A N, n=60$ with $B N$, and $n=60$ with BEDs) and their parents. Mothers, fathers, and youths were assessed through a self-report measure evaluating family functioning, and adolescents completed a self-report questionnaire assessing psychopathological symptoms. Results showed specific family functioning and psychopathological profiles based on adolescents' diagnosis. Regression analyses also showed that family functioning characterized by rigidity predicted higher psychopathological symptoms. Our study underlines the importance of involving all members of the family in assessment and intervention programs when adolescent offspring suffer from EDs.
\end{abstract}

Keywords: family functioning, eating disorders, adolescents, psychopathological risk

\section{Introduction}

Research has shown that eating disorders (EDs) and psychopathological symptoms among female adolescents are associated with problematic family functioning. ${ }^{1-4}$ EDs are common and serious mental disorders characterized by abnormal eating habits and severe subjective concern about body weight or shape, which typically occur at the beginning of puberty or in late adolescence. ${ }^{5}$ In fact, early adolescence and puberty (11-14 years of life) represent transitional phases of life characterized by physical, psychological, and social modifications..$^{6-8}$ In these stages, teenagers experience major and fast body changes, such that puberty could become a period of concern for body size and shape. ${ }^{9}$ Moreover, the brain and the cognitive functions mature, there is an increased awareness of societal pressures for thinness and an increased concern about peer acceptance. ${ }^{10,11}$ For these reasons, although EDs can occur in individuals of all ages, adolescence represents a peak period for their onset. ${ }^{12}$ Recent epidemiological research has shown that prevalence of EDs among adolescents is estimated to be $0.3 \%$ for anorexia nervosa $(\mathrm{AN}), 0.9 \%$ for bulimia nervosa $(\mathrm{BN})$, and $1.6 \%$ for binge eating disorder (BED). ${ }^{13,14}$ Notwithstanding an increase of incidence of EDs in adolescent males over the last few decades, ${ }^{15}$ EDs predominantly affect female adolescents, with a rate of $5.7 \%$ for girls versus $1.2 \%$ for boys $;{ }^{16}$ moreover, adolescent girls usually show
Correspondence: Luca Cerniglia Faculty of Psychology, International Telematic University UNINETTUNO, Corso Vittorio Emanuele II, 39. 00I00, Rome, Italy

Tel +3906 69207625

Email l.cerniglia@uninettunouniversity.net

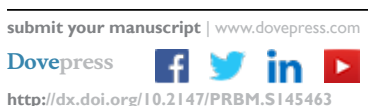

http://dx.doi.org/10.2147/PRBM.S145463 
more severe symptoms of $\mathrm{AN}, \mathrm{BN}$, and BED if compared to same-age boys. ${ }^{17}$

As suggested by many studies, based on a transactional theoretical framework, diagnosis of EDs in early adolescence is associated with both specific maladaptive family functioning and individual vulnerability. ${ }^{1,18}$ In particular, with regard to individual characteristics, although most studies have demonstrated a possible comorbidity between EDs and other psychiatric disorders (e.g., borderline personality disorders, avoidant personality disorders and depression [DEP]), ${ }^{19,20}$ other studies have shown significant associations also with various subclinical forms of psychological difficulties. ${ }^{21-23}$ Research has widely demonstrated that eating pathology in adolescent females is associated with emotional regulation difficulties, which are in turn correlated with obsessive-compulsive/ perfectionistic and impulsive personality traits. ${ }^{24-26}$ Furthermore, empirical studies have evidenced that emotional disturbance can be a predisposing factor for internalizing and externalizing problems in adolescents affected by EDs. ${ }^{27}$ In this regard, genetic and epigenetic research have shown that EDs are associated with both internalizing problems (e.g., anxiety [ANX], withdrawal, and depressive symptoms) and externalizing difficulties, including under-controlled, impulsive, and disinhibited cognitions and behaviors. ${ }^{28-30}$ With regard to family factors, recent studies have found associations between the difficulties of adolescents with EDs and family functioning, but no study, to our best knowledge, has investigated the impact of family psychopathological profiles on the adolescents' psychopathological symptoms, differentiating for different types of EDs, during adolescence.

Indeed, increased demand for autonomy, which characterized the adolescence phase, ${ }^{31}$ fosters a reorganization of family functioning, ${ }^{32}$ and in particular, empirical studies have shown that various characteristics of family functioning (e.g., the presence of excessive dependence on other family members, low flexibility, poor communication, and avoidance of conflict) are associated with unhealthy weightrelated behaviors, disordered eating behaviors, ${ }^{33}$ and higher ED psychopathology, ${ }^{34,35}$ especially among daughters. ${ }^{36,37}$ It must be acknowledged that family pathology may be a result of the offspring disorder rather than its cause. ${ }^{38}$ Within family system theory, Minuchin et $\mathrm{l}^{39,40}$ have defined these families as "psychosomatic families", ${ }^{41}$ highlighting that they are characterized by high levels of overprotectiveness, enmeshment, rigidity, and lack of conflict resolution, although efforts to empirically identify the psychosomatic family have generally been unsuccessful. ${ }^{42}$ Furthermore, according to Olson's Circumplex Model, these families may show unbalanced levels of cohesion (enmeshed families) and flexibility (rigid families). ${ }^{43}$ The experience of unsatisfying family relationships has been suggested to be associated in offspring with many psychological dimensions, such as significant body dissatisfaction, the beauty ideal, maturity fears, interpersonal safety, perfectionism, and self-awareness. ${ }^{34,44}$ Moreover, Kivisto et $\mathrm{al}^{45}$ found that adolescents who perceived higher family enmeshment also demonstrated greater emotional dysregulation in several domains, such as negative global appraisals of distress tolerance and a stronger increase in subjective negative mood. In a recent study, we investigated the differences in perceptions of family functioning of adolescents with EDs and their parents in a developmental psychopathology framework. ${ }^{46}$ This study found that different perceptions of family functioning and peculiar psychopathological vulnerabilities were associated with the diagnosis of ED of adolescents. ${ }^{47-49}$

Based on the abovementioned premises and on our previous results, but building on a systemic-relational framework and assessing a new sample of adolescents and parents, in the present study, we aimed to assess the functioning of families with adolescents with EDs and to verify whether the characteristics of family functioning are associated with a specific form of ED in their offspring and with adolescents' psychopathological profiles.

\section{Methods}

\section{Participants}

Among the total number of female adolescents $(\mathrm{N}=551$; age range: 14-17 years) who visited a network of public and private consultants in central Italy, requesting clinical support for disordered eating, over a 1-year period (from January 2014 to February 2015), 329 adolescents were diagnosed by a group of trained psychologists for EDs according to the Diagnostic and Statistical Manual of Mental Disorders, Fifth Edition (DSM-5) criteria and recruited for this study. ${ }^{50}$ From this sample, $n=86$ adolescents were diagnosed in comorbidity with other psychiatric disorders ( $n=42$ with ANX disorders, $n=31$ with borderline personality disorder, and $n=13$ with DEP) and were excluded from the present study to remain focused on specific features of EDs. The sample fitting the inclusion criteria $(n=239)$ was balanced for age and diagnosis, resulting in $\mathrm{n}=181$ female adolescents (average age $=14.09$ years), diagnosed with AN $(n=61), B N$ $(\mathrm{n}=60)$ and $\operatorname{BED}(\mathrm{n}=60)$.

The families were $93.92 \%$ Caucasian, and most of the families $(88.95 \%)$ had a middle-middle/middle-high socioeconomic level according to the Hollingshead's social status 
index. ${ }^{51}$ A large majority (92.82\%) of families were intact family groups and lived with both parents. In all, $87 \%$ of adolescents were first-born children for both parents.

\section{Procedure}

The research described here was approved by the ethics committee of the Psychology Faculty at Sapienza, University of Rome, before the start of the study and was in accordance with the Declaration of Helsinki. After the first assessment interview and before starting the treatment plan, all adolescents and their families agreed to participate in the study (no attrition was found). All parents signed informed consents, and adolescents gave their assent. Researchers in person administered the self-report questionnaires (described later), and adolescents and their parents filled out the questionnaires independently. Parents and adolescents filled out the Family Adaptability and Cohesion Evaluation Scale (FACES), and adolescents also completed the Symptom Checklist-90 Items-Revised (SCL-90-R). All measures were completed at the time of distribution.

\section{Measures}

The SCL-90-R is a 90 -item self-report symptom inventory designed to measure psychological symptoms and psychological distress. ${ }^{52}$ The SCL-90-R is rated on a Likert scale of 0 (not at all) to 4 (extremely) and asks participants to report whether they have suffered in the past week from symptoms that are scored and interpreted in terms of nine dimensions: somatization (SOM; e.g., headaches), obsessive-compulsivity (O-C; e.g., unwanted thoughts, words, or ideas that would not leave your mind), interpersonal sensitivity (I-S; e.g., feeling critical of others), DEP (e.g., loss of sexual interest or pleasure), ANX (e.g., nervousness or shakiness inside), hostility (HOS; e.g., feeling easily annoyed or irritated), phobic anxiety (PHOB; e.g., feeling afraid in open spaces or on the streets), paranoid ideation (PAR; e.g., feeling others are to blame for most of your troubles), and psychoticism (PSY; e.g., the idea that someone else can control your thoughts). Furthermore, it is scored on three global indices of distress, Global Severity Index (GSI), Positive Symptom Distress Index (PSDI), and Positive Symptom Total (PST). Prunas et $\mathrm{a}^{53}$ demonstrated a satisfactory internal consistency of the Italian version of the SCL-90-R in adolescents and adults ( $\alpha$ coefficient, $0.70-0.96$ ). Scores higher than the clinical cut-off ( $\geq 1$ in GSI) indicate psychopathological risk.

The FACES-IV is a self-report questionnaire that assesses adolescents' and parents' perceived family functioning. ${ }^{54}$ It is composed of 42 items rated on a Likert scale of 1 (strongly disagree) to 5 (strongly agree). The FACES-IV is scored on six scales: two balanced scales, cohesion and flexibility, assessing central-moderate areas and four unbalanced scales, enmeshed, disengaged, chaotic, and rigidity, assessing the lower and the upper ends of cohesion and flexibility. Higher scores on the balanced scales are linked with higher levels of adaptive family functioning, while higher scores on the unbalanced scales indicate more problematic family functioning. In the present study, reliability of the six FACES-IV scales was as follows: enmeshed $=0.78$, disengaged $=0.86$, balanced cohesion $=0.87$, , haotic $=0.85$, balanced flexibility $=0.84$, and rigid $=0.85$. The $\alpha$ reliability was very good for all six scales. ${ }^{54}$ In addition, two additional scales within the FACES-IV battery have been included: Family Satisfaction Scale (FSS) and Family Communication Scale (FCS). The FCS is a 10-item scale developed to measure communication in families with an adolescent, which can be used with a variety of family forms, and families at various life-cycle stages related to the Circumplex Model. The internal consistency reliability of the FCS is 0.90 and the test-retest reliability is 0.86 . In this study, internal consistency reliability is 0.84 . The FSS is a 10-item scale, developed by $\mathrm{Olson}^{55}$ in relation to the Circumplex Model, and it is intended as a part of FACESIV. The scale assesses the degree of satisfaction with aspects related to family cohesion and flexibility. The FSS has an alpha reliability of 0.93 and test-retest reliability of 0.85 . In this study, internal consistency reliability is 0.91 and we used the normative scores of the Italian version of FACESIV and family members' scores were averaged to yield an overall family score. ${ }^{54-56}$

\section{Statistical analysis}

The statistical package SPSS 23.0 was used for all analyses. Adolescents', mothers', and fathers' scores on FACES-IV were coded in accordance with the author's instructions. ${ }^{54}$

In order to assess family functioning, analysis of variance (ANOVA) was conducted identifying the groups (Group A: subjects with AN, Group B: subjects with BN, and Group $\mathrm{C}$ : subjects with $\mathrm{BED}$ ) as the independent variables, and all of the dimensions of the FACES-IV were identified as the dependent variables. Families' scores were compared with the mean scores of the Italian population.

ANOVAs were conducted to verify possible significant differences between the three study groups on adolescents' psychopathological risk. The post hoc analyses were conducted using the Scheffe's method. To evaluate the clinical relevance of the scores identified, cutoff values for the Italian population were used. Finally, to evaluate the possible 
predictive power of family functioning on adolescents' psychopathological risk in the different groups, a series of hierarchical regressions were conducted, also assessing the possible effects of interaction. Missing data ( $2 \%$ for each instrument) for all applicable analyses were corrected using multiple imputations in the SPSS software (Version 23.0).

\section{Results}

\section{Assessment of family functioning}

To verify a possible significant difference on family functioning in families with adolescents diagnosed with $\mathrm{AN}, \mathrm{BN}$, and BED, an ANOVA was conducted considering the mean scores in the perception of family functioning of fathers, mothers, and adolescents on FACES-IV in Groups A, B, and C. Figure 1 shows family functioning profiles of families with adolescents diagnosed with different EDs.

As it is possible to see, there are differences in family profiles between the three diagnostic groups. Furthermore, all family profiles diverge from the profile identified by Olson ${ }^{55}$ for balanced families. Table 1 lists significant differences between the mean scores of the three groups and those of balanced families.

Results of ANOVA showed that families with adolescents diagnosed with AN (Group A) showed higher scores than other groups on FACES-IV subscales enmeshment $(p<0.001)$ and rigidity ( $p<0.001$ compared to Group $\mathrm{C}$; $p<0.05$ compared to Group B) and lower scores on subscales cohesion $(p<0.001$, compared to Group C), communication $(p<0.001$, compared to Group C), and chaotic ( $p<0.001$, compared to other groups). Families with adolescents diagnosed with BN
(Group B), instead, had higher scores on chaotic $(p<0.001)$ than Group A and lower scores on cohesion $(p<0.001$, compared to Group C) and flexibility $(p<0.001)$ compared to other groups. Furthermore, families with adolescents diagnosed with BEDs (Group C) had higher scores on cohesion $(p<0.001)$, flexibility $(p<0.001)$, and communication $(p<0.001)$ than Groups A and B.

\section{Assessment of adolescents' psychopathological risk}

To verify a possible significant difference in the scores of adolescents' psychopathological risk in the three study groups, an ANOVA was conducted. Group factor (Group A: subjects with Z, Group B: subjects with BN, and Group C: subjects with $\mathrm{BED}$ ) was identified as the independent variable and all SCL-90-R subscales were identified as the dependent

Table I Differences between the mean scores of the three groups (Group A: AN, Group B: BN, and Group C: BED) and those of balanced families

\begin{tabular}{lllll}
\hline $\begin{array}{l}\text { FACES-IV } \\
\text { subscales }\end{array}$ & Group A & Group B & Group C & $\begin{array}{l}\text { Balanced } \\
\text { families }\end{array}$ \\
\hline Cohesion & $35.31^{*}$ & $37.52^{*}$ & $53.19^{*}$ & 83 \\
Flexibility & $33.32^{*}$ & $23.6^{*}$ & $42.57^{*}$ & 80 \\
Disengagement & $66.41^{*}$ & $69.84^{*}$ & $73.54^{*}$ & 27 \\
Enmeshment & $79.37^{*}$ & $69.6^{*}$ & $74.19^{*}$ & 38 \\
Rigidity & $69.46^{*}$ & $61.77^{*}$ & $46.58^{*}$ & 35 \\
Chaotic & $70.62^{*}$ & $94.31^{*}$ & $92.76^{*}$ & 33 \\
\hline
\end{tabular}

Note: *Significantly different $(p<0.00 \mathrm{I})$ from balanced families' mean scores (onesample $t$-test).

Abbreviations: $\mathrm{AN}$, anorexia nervosa; $\mathrm{BN}$, bulimia nervosa; $\mathrm{BED}$, binge eating disorder; FACES, Family Adaptability and Cohesion Evaluation Scale.

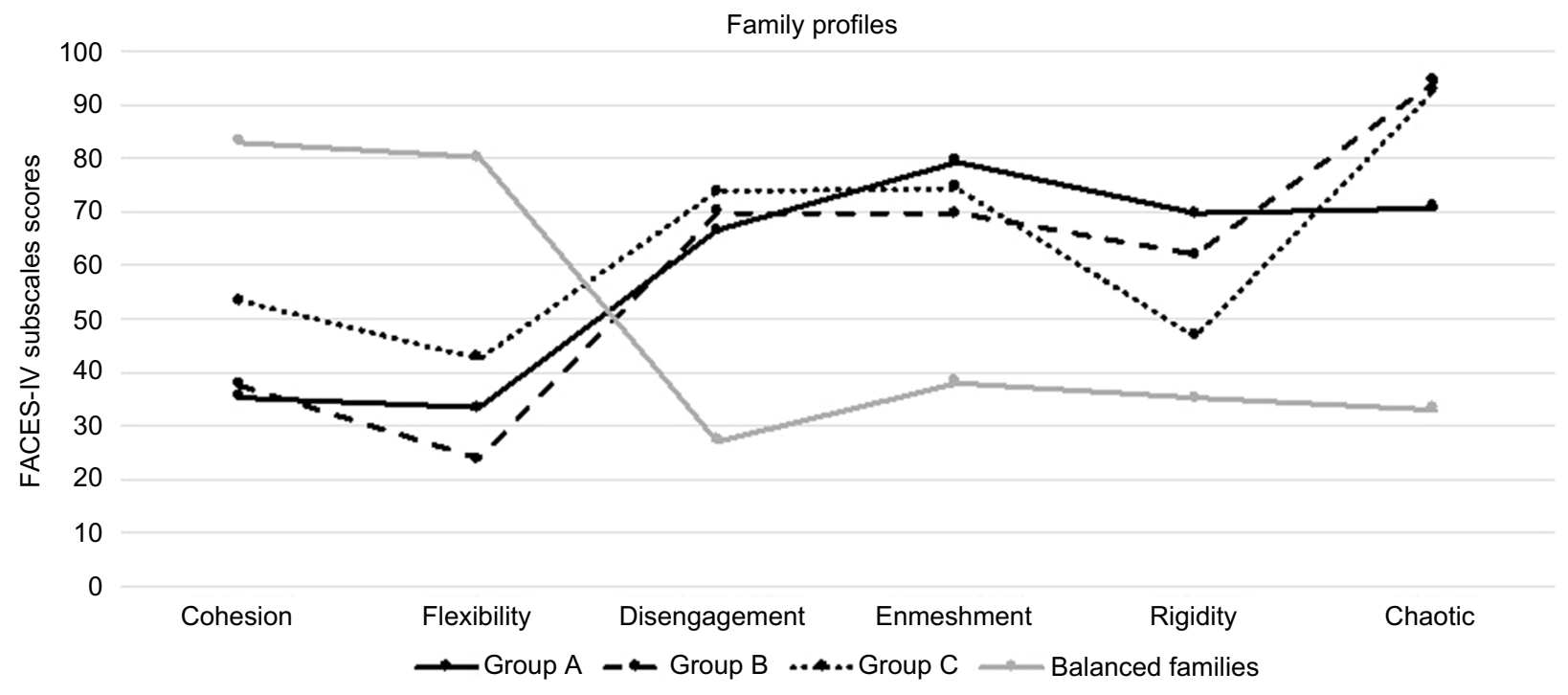

Figure I Family profiles of families with adolescents affected by AN (Group A), BN (Group B), and BED (Group C).

Abbreviations: AN, anorexia nervosa; BN, bulimia nervosa; BED, binge eating disorder; FACES, Family Adaptability and Cohesion Evaluation Scale. 
variables. Results showed significant differences between groups on psychopathological profiles (Table 2).

Results showed that adolescents of Groups A, B, and C had specific characteristics in their psychopathological profiles. In particular, adolescents diagnosed with AN had the highest psychopathological risk. Moreover, adolescents of Group A showed mean scores that exceeded the clinical cutoff in all SCL-90-R subscales and had higher scores on subscales ANX ( $p<0.001$, compared to Group C), O-C ( $p<0.001)$, DEP $(p<0.001)$, HOS $(p<0.001)$, and GSI $(p<0.01)$ if compared to other groups. On the other hand, adolescents of Group B showed higher scores on SOM $(p<0.001)$, PAR $(p<0.001)$, and PHOB $(p<0.001)$ than other groups and exceeded clinical cutoff in these subscales. Furthermore, adolescents of Group $\mathrm{C}$ showed higher scores on I-S $(p<0.001)$ and PSY $(p<0.001)$ compared to Groups A and B and exceeded clinical cutoff in these subscales.

\section{Associations between family functioning and adolescents' psychopathology}

A series of hierarchical regressions were conducted to evaluate the possible associations between family functioning and adolescents' psychopathology. Results showed that family functioning is associated with adolescents' psychopathological risk, differently in the three groups. Regression analysis on Group A showed that higher scores on the FACES-IV subscale rigidity predicted higher scores on adolescents' SOM $\left(R^{2}=0.224 ; \beta=0.303 ; t=2.24 ; p<0.05\right)$, and higher scores on FACES-IV subscale enmeshment predicted higher scores on

Table 2 Means, standard deviations, and cutoff values of adolescents' scores on SCL-90-R (Group A: adolescents with AN, Group B: adolescents with BN, and Group C: adolescents with BED)

\begin{tabular}{lllll}
\hline $\begin{array}{l}\text { SCL-90-R } \\
\text { subscales }\end{array}$ & Group A & Group B & Group C & Cutoff \\
\hline SOM & $\mathrm{I} .04(0.4 \mathrm{I})$ & $3.5(0.27)^{*}$ & $0.88(0.54)$ & $>\mathrm{I} .03$ \\
O-C & $3.44(0.36)^{*}$ & $0.87(0.54)$ & $0.86(0.62)$ & $>\mathrm{I} .03$ \\
I-S & $\mathrm{I} .19(0.56)$ & $0.84(0.5)$ & $3.46(0.53)^{*}$ & $>0.9 \mathrm{I}$ \\
DEP & $3.46(0.2)^{*}$ & $0.89(0.52)$ & $0.85(0.66)$ & $>\mathrm{I} . \mathrm{II}$ \\
ANX & $\mathrm{I} .15(0.5 \mathrm{I})^{*}$ & $\mathrm{I} .0 \mathrm{I}(0.48)$ & $0.79(0.66)$ & $>0.9 \mathrm{I}$ \\
HOS & $3.44(0.4)^{*}$ & $\mathrm{I} .04(0.56)$ & $0.68(0.7)$ & $>0.83$ \\
PHOB & $\mathrm{I}(0.42)$ & $3.48(0.27)^{*}$ & $0.9(0.55)$ & $>0.58$ \\
PAR & $\mathrm{I} .04(0.45)$ & $3.52(0.29)^{*}$ & $0.85(0.63)$ & $>0.9 \mathrm{I}$ \\
PSY & $\mathrm{I} .08(0.5 \mathrm{I})$ & $0.9 \mathrm{I}(0.42)$ & $3.5 \mathrm{I}(0.35)^{*}$ & $>0.42$ \\
GSI & $\mathrm{I} .82(0.22)^{*}$ & $\mathrm{I} .64(0.25)$ & $\mathrm{I} .4 \mathrm{I}(0.42)$ & $>\mathrm{I}$ \\
\hline
\end{tabular}

Notes: ${ }^{*} p<0.01$. Data presented as mean (standard deviation).

Abbreviations: SCL-90-R, Symptom Checklist-90 Items-Revised; AN, anorexia nervosa; BN, bulimia nervosa; BED, binge eating disorder; SOM, somatization; O-C, obsessive-compulsivity; I-S, interpersonal sensitivity; DEP, depression; ANX, anxiety; HOS, hostility; PHOB, phobic anxiety; PAR, paranoid ideation; PSY, psychoticism; GSI, Global Severity Index. adolescents' ANX $\left(R^{2}=0.29 ; \beta=0.37 ; t=2.57 ; p<0.05\right)$. Furthermore, regression analysis on Group B showed that higher scores on FACES-IV subscale rigidity predicted higher scores on adolescents' DEP $\left(R^{2}=0.202 ; \beta=0.45 ; t=2.64 ; p<0.05\right)$ and that lower scores on communication predicted higher scores on I-S $\left(R^{2}=0.26 ; \beta=-0.45 ; t=-3.04 ; p<0.01\right)$ and lower scores on satisfaction predicted higher scores on $\operatorname{HOS}\left(R^{2}=0.26 ; \beta=-0.32\right.$; $t=-2.21 ; p<0.05)$. Finally, the regression analysis on Group $\mathrm{C}$ showed that higher scores on FACES-IV subscale rigidity predicted higher scores on I-S $\left(R^{2}=0.19 ; \beta=0.34 ; t=2.21 ; p<0.05\right)$.

\section{Discussion}

The present study aimed to investigate the possible associations between family functioning and psychopathological symptoms in adolescents with EDs. We aimed to verify the existence of specific profiles of family functioning and specific psychopathological symptoms in adolescents diagnosed with AN, BN, and BED. Our results showed that families of female adolescents with EDs are characterized by specific problematic profiles of family functioning. As shown in Figure 1, all family profiles diverge from the profile identified by Olson ${ }^{57}$ for balanced families, which showed higher levels of cohesion and flexibility and lower scores on the subdimensions of disengagement, enmeshment, rigidity, and chaotic. Moreover, there are significant differences between family profiles in the three diagnostic groups. In particular, families with adolescents diagnosed with AN tend to report interpersonal boundary problems, poor tolerance of conflicts, and low levels of general satisfaction in their family. Specifically, they showed significantly higher scores of enmeshment and rigidity and lower scores of cohesion, chaotic, and communication quality. These results are consistent with previous studies that indicated the presence of excessive dependence on other family members, low flexibility, poor communication, and overprotectiveness in these families. ${ }^{18,58}$ These features seem to be coherent with conflict avoidance, which generally characterizes familial relationship of families with daughters diagnosed with AN. ${ }^{59}$

Parents of adolescents diagnosed with $\mathrm{BN}$ described their families as more chaotic than parents in families with adolescents diagnosed with AN, with lower levels of flexibility and cohesion than all other groups. In addition, Vidović et $\mathrm{al}^{60}$ suggested that families of adolescents with bulimic diagnosis have a significantly more dysfunctional family background compared to patients diagnosed with AN. The families of bulimic adolescents represented their families as less cohesive, poorly coherent, and badly organized and reported the presence of high levels of family conflict and 
distress. ${ }^{46,61}$ Finally, families of adolescents diagnosed with BED showed higher scores of cohesion and flexibility, and similar to families with daughters suffering from AN, they described their family as enmeshed and characterized by poor communication. These findings are coherent with the study of Tetzlaff et $\mathrm{al}^{37}$ that has suggested that families of female adolescents with BED showed significantly low emotional and affective involvement; other studies also underlined that they tend to report nonaffective communication and low adaptability. ${ }^{62}$

With regard to adolescents' psychopathological risk, our study found that Groups A, B, and C presented specific psychopathological profiles. In particular, adolescents with AN reported the highest levels of psychopathological risk, exceeding the clinical cutoffs for the Italian population in all SCL-90-R subscales, and they reported greater obsessivecompulsive symptomatology, DEP, HOS, and ANX. Adolescents with BN (Group B) showed more difficulties on SOM and PHOB. On the other hand, adolescents suffering from BED had higher scores of I-S and PSY. Our results are in line with international scientific literature that underlines that adolescents suffering from an ED can present a wide range of subclinical forms of psychological problems, specifically in the internalizing area. ${ }^{21,22,63}$ Results also showed that families with adolescents diagnosed with $\mathrm{AN}, \mathrm{BN}$, and BED had different profiles of family functioning and that their daughters showed psychopathological risk in different problematic areas. Thus, we aimed to verify the possible association of family functioning with adolescents' psychopathological risk. Regression analysis confirmed this association. In particular, as previously found by Allen et al, ${ }^{64}$ in adolescents with $\mathrm{AN}$, higher rigidity in familial relationship predicts higher levels of SOM, whereas higher enmeshment is predictive of higher ANX. In adolescents with $\mathrm{BN}$, higher levels of rigidity are associated with higher scores of DEP, poorer quality of communication predicts higher scores of I-S, and lower levels of satisfaction are associated with higher scores of I-S. Finally, higher scores of rigidity in families with adolescents with BED are predictive of higher levels of I-S. These results are consistent with the findings of one previous study that have suggested that dysfunctional family functioning is associated with a higher psychopathological risk in adolescents with EDs. ${ }^{65}$ Interestingly, our results also showed that rigidity, which characterizes family functioning in families with daughters with EDs, predicts higher psychopathological symptoms, but with different configurations in the three diagnostic groups. Everri et al ${ }^{66}$ underlined that when rigidity is associated with disengagement, low cohesion and flexibility could be considered as maladaptive. Furthermore, Lampis et $\mathrm{al}^{67}$ have shown that high levels of cohesion and family adaptability were protection factors for EDs.

The present study has several strengths. First, the study took into consideration three groups of adolescents diagnosed with different EDs, assessing adolescents' psychopathological risk and family functioning. Second, the measures used are well validated and are widely used. ${ }^{52,54}$ Third, our research assesses parents' and adolescents' perceived quality of family functioning, considering mean scores aggregating the scores of family members, which may constitute a strong stimulus for further clinical studies. Studies addressing specific forms of EDs and their associations with psychopathological profiles and family functioning are scarce. The present study may add to previous literature and supports clinical work in the treatment of adolescents diagnosed with EDs, as suggested by Jewell et al. ${ }^{68}$ In fact, clinicians could organize different interventions depending on the particular ED the adolescent is manifesting and the specific familial functioning (represented for instance by their members' capacity to adaptively communicate, support each other, and be flexible).

Our study has some limitations. We did not recruit a control sample, and it has not been possible to compare subjects' scores to a nonclinical group. On the other hand, we used the normative scores for the Italian population for both measures. Furthermore, we did not assess parental psychopathological risk, which could give important information on the development of adolescents' EDs. ${ }^{46,69-71}$ In addition, the homogeneity of the sample, in terms of cultural, geographical, and socioeconomic status, limits replication of the study in other countries or cultures. Finally, the present study did not take into consideration social support, which several studies underline to be important in the adolescent phase, ${ }^{72,73}$ and longitudinal studies are needed that can clarify the many dynamics. ${ }^{74,75}$

\section{Disclosure}

The authors report no conflicts of interest in this work.

\section{References}

1. Levine M, Smolak L. Toward a model of the developmental psychopathology of eating disorders: the example of early adolescence. In: Crowter JH, Hobfoll SE, Stephens MA, Tennenbaum DL, editors. The Etiology of Bulimia Nervosa: The Individual and Familial Context. Washington: Taylor and Francis; 2013:59-80.

2. Tafà M, Baiocco R. Addictive behavior and family functioning during adolescence. J Fam Ther. 2009;37:388-395.

3. Amianto F, Ercole R, Marzola E, Abbate Daga G, Fassino S. Parents' personality clusters and eating disordered daughters' personality and psychopathology. Psychiatry Res. 2015;230(1):19-27. 
4. Visani E. Studi sul funzionamento familiare: osservazioni complessive. In: Visani E, Di Nuovo S, Loriedo C, editors. Faces IV. Il ModelloCirconflesso di Olson nella clinica e nella ricerca. Milano: Franco Angeli; 2014:148-152.

5. Klump KL. Puberty as a critical risk period for eating disorders: a review of human and animal studies. Horm Behav. 2013;64(2):399-410.

6. Brooks-Gunn J. Pubertal processes and girls' psychological adaptation. In: Lerner R, Foch TT, editors. Biological-Psychosocial Interactions in Early Adolescence: A Life-Span Perspective. Hillsdale, NJ: Lawrence Erlbaum Associates; 1987:123-153.

7. Paciello M, Fida R, Tramontano C, Cole E, Cerniglia L. Moral dilemma in adolescence: the role of values, prosocial moral reasoning and moral disengagement in helping decision making. Eur J Dev Psychol. 2013;10(2):190-205.

8. Monacis L, de Palo V, Griffiths MD, Sinatra M. Exploring individual differences in online addictions: the role of identity and attachment. Int J Ment Health Addict. 2017;15(4):853-868.

9. Patel P, Wheatcroft R, Park RJ, Stein A. The children of mothers with eating disorders. Clin Child Fam Psychol Rev. 2002;5:1-19.

10. Steinberg LD. Adolescence. 5th ed. New York: McGraw-Hill; 1999.

11. Cerniglia L, Cimino S, Ballarotto G, et al. Motor vehicle accidents and adolescents: an empirical study on their emotional and behavioral profiles, defense strategies and parental support. Transp Res Part F Traffic Psychol Behav. 2015;35:28-36.

12. Poppe I, Simons A, Glazemakers I, Van West D. Early-onset eating disorders: a review of the literature. Tijdschr Psychiatr. 2015;57(11):805-814.

13. Swanson SA, Crow SJ, Le Grange D, Swendsen J, Merikangas KR. Prevalence and correlates of eating disorders in adolescents: results from the national comorbidity survey replication adolescent supplement Arch Gen Psychiatry. 2011;68(7):714-723.

14. Hay P, Girosi F, Mond J. Prevalence and sociodemographic correlates of DSM-5 eating disorders in the Australian population. J Eat Disord. 2015;3:19.

15. Sepulveda AR, Carrobles JA, Gandarillas AM. Gender, school and academic year differences among Spanish University students at highrisk for developing an eating disorder: an epidemiologic study. $B M C$ Public Health. 2008;28(8):102.

16. Smink FR, van Hoeken D, Oldehinkel AJ, Hoek HW. Prevalence and severity of DSM-5 eating disorders in a community cohort of adolescents. Int J Eat Disord. 2014;47(6):610-619.

17. Sidor A, Baba CO, Marton-Vasarhelyi E, Chereches RM. Gender differences in the magnitude of the associations between eating disorders symptoms and depression and anxiety symptoms. Results from a community sample of adolescents. J Ment Health. 2015;24(5):294-298.

18. Berge JM, Loth K, Hanson C, Croll-Lampert J, Neumark-Sztainer D Family life cycle transitions and the onset of eating disorders: a retrospective grounded theory approach. J Clin Nurs. 2012;21(9-10):1355-1363.

19. Strober M, Katz JL. Depression in the eating disorders: a review and analysis of descriptive, family and biological findings. Diagnostic issues in anorexia nervosa and bulimia nervosa. In: Garner DM, Garfinkel PE, editors. Diagnostic Issues in Anorexia Nervosa and Bulimia Nervosa. New York: Brunner/Mazel; 1988:80-111.

20. Pope HG, Hudson JI. Are eating disorders associated with borderline personality disorder? A critical review. Int J Eat Disord. 1989;8:1-9.

21. Stice E, Marti CN, Durant S. Risk factors for onset of eating disorders: evidence of multiple risk pathways from an 8-year prospective study. Behav Res Ther. 2011;49(10):622-627.

22. Lucarelli L, Cimino S, D’Olimpio F, Ammaniti M. Feeding disorders of early childhood: an empirical study of diagnostic subtypes. Int J Eat Disord. 2013;46(2):147-155.

23. Tambelli R, Cerniglia L, Cimino S, et al. An exploratory study on the influence of psychopathological risk and impulsivity on BMI and perceived quality of life in obese patients. Nutrients. 2017;9(5):11.

24. Thompson-Brenner H, Eddy KT, Satir DA, Boisseau CL, Westen D. Personality subtypes in adolescents with eating disorders: validation of a classification approach. J Child Psychol Psychiatry. 2008;49(2):170-180.
25. Monell E, Högdahl L, Forsén Mantilla E, Birgegård A. Emotion dysregulation, self-image and eating disorder symptoms in University Women. J Eat Disord. 2015;3:44.

26. Parolin M, Simonelli A, Cristofalo P, et al. Drug addiction and emotional dysregulation in young adults. Heroin Addict Relat Clin Probl. 2017;19(3):37-48.

27. Gilboa-Schechtman E, Avnon L, Zubery E, Jeczmien P. Emotional processing in eating disorders: specific impairment or general distress related deficiency? Depress Anxiety. 2006;23(6):331-339.

28. Kendler KS, Aggen SH, Knudsen GP, Røysamb E, Neale MC, Reichborn-Kjennerud T. The structure of genetic and environmental risk factors for syndromal and subsyndromal common DSM-IV axis I and all axis II disorders. Am J Psychiatry. 2011;168(1):29-39.

29. Babore A, Trumello C, Candelori C, Paciello M, Cerniglia L. Depressive symptoms, self-esteem and perceived parent-child relationship in early adolescence. Front Psychol. 2016;7:982.

30. Cerniglia L, Zoratto F, Cimino S, Laviola G, Ammaniti M, Adriani W. Internet addiction in adolescence: neurobiological, psychosocial and clinical issues. Neurosci Biobehav Rev. 2017;76(pt A):174-184.

31. Eccles JS, Midgley C, Wigfield A, et al. Development during adolescence: the impact of stage-environment fit on young adolescents' experiences in schools and in families. Am Psychol. 1993;48(2):90-101.

32. O'Connell ME, Boat T, Warner KE. Preventing Mental, Emotional, and Behavioral Disorders among Young People: Progress and Possibilities. Washington, DC: The National Academic Press; 2009.

33. Berge JM, Wall M, Larson N, Eisenberg ME, Loth KA, NeumarkSztainer D. The unique and additive associations of family functioning and parenting practices with disordered eating behaviors in diverse adolescents. J Behav Med. 2014;37(2):205-217.

34. Wisotsky W, Dancyger I, Fornari V, Katz J, Wisotsky WL, Swencionis C. The relationship between eating pathology and perceived family functioning in eating disorder patients in a day treatment program. Eat Disord. 2003;11(2):89-99.

35. le Grange D, Lock J, Loeb K, Nicholls D. Academy for Eating Disorders position paper: the role of the family in eating disorders. Int J Eat Disord. 2010;43(1):1-5.

36. Lyke J, Matsen J. Family functioning and risk factors for disordered eating. Eat Behav. 2013;14(4):497-499.

37. Tetzlaff A, Schmidt R, Brauhardt A, Hilbert A. Family functioning in adolescents with binge-eating disorder. Eur Eat Disord Rev. 2016;24:430-433.

38. Eisler I. The empirical and theoretical base of family therapy and multiple family day therapy for adolescent anorexia nervosa. J Fam Ther. 2005;27(2):104-131.

39. Minuchin S, Fishman HC. Psychosomatic family in child psychiatry. J Am Acad Child Psychiatry. 1980;18(1):76-90.

40. Minuchin S, Rosman BL, Baker L. Psychosomatic Families: Anorexia Nervosa in Context. Cambridge, MA: Harward University Press; 1978.

41. Wood B, Watkins JB, Boyle JT, Nogueira J, Zimand E, Carroll L. The "Psychosomatic Family" Model: an empirical and theoretical analysis. Fam Process. 1989;28:399-417.

42. Dare C, Grange DL, Eisler I, Rutherford J. Redefining the psychosomatic family: family process of 26 eating disorder families. Int J Eat Disord. 1994;16(3):211-226.

43. Olson DH. Family assessment and intervention: the Circumplex Model of family systems. Child Youth Serv. 1988;11:9-48.

44. Franko DL, Thompson D, Affenito SG, Barton BA, Striegel-Moore RH. What mediates the relationship between family meals and adolescent health issues. Health Psychol. 2008;27(2):S109-S117.

45. Kivisto KL, Welsh DP, Darling N, Culpepper CL. Family enmeshment, adolescent emotional dysregulation, and the moderating role of gender. J Fam Psychol. 2015;29(4):604-613.

46. Tafà M, Cimino S, Ballarotto G, Bracaglia F, Bottone C, Cerniglia L. Female adolescents with eating disorders, parental psychopathological risk and family functioning. J Child Fam Stud. 2016;26(1):28-39.

47. Feetham SL. Feetham Family Functioning Survey. Washington, DC: Children's Hospital National Medical Center; 1988. 
48. Lanz M, Rosnati R. Metodologia della ricerca sulla famiglia. Milano: Led; 2002.

49. Mazzoni S, Tafà M. Methodological problems for the study of family realtionships [Problemi metodologici nello studio delle relazioni familiari.] In: Mazzoni S, Tafà M, editors. Intersubjectivity in the family. Multimethod procedures for the observation and assessment of family relationships. [L'intersoggettività nella famiglia. Procedure multimetodo per l'osservazione e la valutazione delle relazioni familiari.] Milano: Franco Angeli; 2007:53-66.

50. American Psychiatric Association. Diagnostic and Statistical Manual of Mental Disorders (DSM-5). Arlington, VA: American Psychiatric Publishing; 2013.

51. Hollingshead AB. Four Factor Index of Social Status. New Haven, CT: Yale University; 1975.

52. Derogatis LR. Symptom Checklist-90-Revised: Administration, Scoring and Procedures Manual. Minneapolis, MN: National Computer Systems; 1994.

53. Prunas A, Sarno I, Preti E, Madeddu F, Perugini M. Psychometric properties of the Italian version of the SCL-90-R: a study on a large community sample. Eur Psychiatry. 2012;27(8):591-597.

54. Olson DH. FACES IV and the Circumplex Model: validation study. J Marital Fam Ther. 2011;37(1):64-80.

55. Olson DH. Family Satisfaction Scale. Minneapolis, MN: Life Innovations; 1995.

56. Baiocco R, Cacioppo M, Laghi F, Tafà M. Factorial and construct validity of FACES IV among Italian adolescents. $J$ Child Fam Stud. 2013;22:962-970.

57. Olson DH. Data Analysis Using FACES IV Scores. Minneapolis, MN: Life Innovations; 2010.

58. Erol A, Yazici F, Toprak G. Family functioning of patients with an eating disorder compared with that of patients with obsessive compulsive disorder. Compr Psychiatry. 2007;48(1):47-50.

59. Holtom-Viesel A, Allan S. A systematic review of the literature on family functioning across all eating disorder diagnoses in comparison to control families. Clin Psychol Rev. 2014;34(1):29-43.

60. Vidović V, Jureša V, Begovac I, Mahnik M, Tocilj G. Perceived family cohesion, adaptability and communication in eating disorders. Eur Eat Disord Rev. 2005;13(1):19-28.

61. Johnson C, Flach A. Family characteristics of 105 patients with bulimia nervosa. Am J Psychiatry. 1985;142:1321-1324.

62. Meno CA, Hannum JW, Espelage DE, Douglas Low KD. Familial and individual variables as predictors of dieting concerns and binge eating in college females. Eat Behav. 2008;9(1):91-101.

63. Cerniglia L, Muratori P, Milone A, et al. Paternal psychopathological risk and psychological functioning in children with eating disorders and Disruptive Behavior Disorder. Psychiatry Res. 2017;254:60-66.
64. Allen KL, Gibson LY, McLean NJ, Davis EA, Byrne SM. Maternal and family factors and child eating pathology: risk and protective relationships. J Eat Disord. 2014;29(2):11.

65. Wisotsky W, Dancyger I, Fornari V, et al. Is perceived family dysfunction related to comorbid psychopathology? A study at an eating disorder day treatment program. Int J Adolesc Med Health. 2006;18(2): 235-244.

66. Everri M, Mancini T, Fruggeri L. The role of rigidity in adaptive and maladaptive families assessed by FACES IV: the points of view of adolescents. J Child Fam Stud. 2016;25(10):2987-2997.

67. Lampis J, Agus M, Cacciarru B. Quality of family relationships as protective factors of eating disorders: an investigation amongst Italian teenagers. Appl Res Qual Life. 2014;9:309-324.

68. Jewell T, Blessitt E, Stewart C, Simic M, Eisler I. Family therapy for child and adolescent eating disorders: a critical review. Fam Process. 2016;55:577-594.

69. Cerniglia L, Cimino S, Ballarotto G. Mother-child and father-child interaction with their 24-month-old children during feeding, considering paternal involvement and the child's temperament in a community sample. Infant Ment Health J. 2014;35(5):473-481.

70. Tambelli R, Cimino S, Cerniglia L, Ballarotto G. Early maternal relational traumatic experiences and psychopathological symptoms: a longitudinal study on mother- infant and father-infant interactions. Sci Rep. 2015;5:13984.

71. Tambelli R, Cerniglia L, Cimino S, Ballarotto G. Parent-infant interactions in families with women diagnosed with postnatal depression: a longitudinal study on the effects of a psychodynamic treatment. Front Psychol. 2015;6:210.

72. Cerniglia L, Cimino S, Ballarotto G, Monniello G. Parental loss during childhood and outcomes on adolescents' psychological profiles: a longitudinal study. Curr Psychol. 2014;33(4):545-556.

73. Cerniglia L, Cimino S, Ballarotto G, Tambelli R. Erratum to: do parental traumatic experiences have a role in the psychological functioning of early adolescents with binge eating disorder? Eat Weight Disord. 2017;22(2):377.

74. Capobianco M, Pizzuto EA, Devescovi A. Gesture speech combinations and early verbale abilities. New longitudinal data during the second year of age. Interact Stud. 2017;18(1):54-75.

75. Cimino S, Cerniglia L, Porreca A, Simonelli A, Ronconi L, Ballarotto G. Mothers and fathers with binge eating disorder and their 18-36 months old children: a longitudinal study on parent-infant interactions and offspring's emotional-behavioral profiles. Front Psychol. 2016;7:580.
Psychology Research and Behavior Management

\section{Publish your work in this journal}

Psychology Research and Behavior Management is an international, peerreviewed, open access journal focusing on the science of psychology and its application in behavior management to develop improved outcomes in the clinical, educational, sports and business arenas. Specific topics covered in the journal include: Neuroscience, memory and decision making; Behavior modification and management; Clinical applications; Business and sports performance management; Social and developmental studies; Animal studies The manuscript management system is completely online and includes a very quick and fair peer-review system, which is all easy to use. Visit http://www. dovepress.com/testimonials.php to read real quotes from published authors. 